\title{
ARMAMENTO DE SITIO EN EL CASTILLO DE CHINCHILLA (ALBACETE) DURANTE LA GUERRA DEL MARQUESADO DE VILLENA: LA ARTILLERÍA DE HIERRO FORJADO
}

\author{
SIEGE WEAPONRY IN THE CASTLE OF CHINCHILLA \\ (ALBACETE) DURING THE WAR OF THE MARQUISATE OF \\ VILLENA: WROUGHT IRON ARTILLERY
}

\author{
JosÉ LuIS Simón GaRcía \\ Instituto de Estudios Albacetenses \\ Albacete, JCCM, España \\ ORCID iD: http://orcid.org/0000-0002-5118-8790.

Alberto J. LoRrio Alvarado
Universidad de Alicante
Alicante, Comunidad Valenciana, España
ORCID iD: http://orcid.org/0000-0003-1879-4681.

Cómo citar este artículo: Simón García, J. L.; Lorrio Alvarado, A. J. (2021). Armamento de sitio en el castillo de Chinchilla (Albacete) durante la guerra del marquesado de Villena: la artillería de hierro forjado. Al-Basit (66), 399-442. http:// doi.org/10.37927/al-basit.66_10

Recibido/Received: 06-07-2021

Aceptado/Accepted: 10-10-2021

RESUMEN: Presentamos un segundo trabajo sobre las armas recuperadas en las excavaciones del Castillo de Chinchilla (Albacete), en esta ocasión centrado en la Guerra del Marquesado de Villena, en pleno conflicto por la sucesión del reino de Castilla entre don Diego Pacheco, marqués de Villena, apoyando a Juana la Beltraneja, e Isabel la Católica con el apoyo de Fernando de Aragón.

\begin{abstract}
In this paper we present a second study on the weapons recovered from the excavations at Chinchilla Castle (Albacete), this time focused on the War of the Marquis of Villena, in full conflict over the succession of the kingdom of Castilla between Don Diego Pacheco, Marquis of Villena, supporting Juana la Beltraneja and Isabel la Católica with the support of Fernando de Aragón.
\end{abstract}


PALABRAS CLAVE: Guerra del Marquesado de Villena, artillería de hierro forjado, Chinchilla, Albacete.
KEY WORDS: War of the Marquis of Villena, wrought iron artillery, Chinchilla, Albacete.

\section{INTRODUCCIÓN}

En el estudio de la poliorcética de los castillos y torres de la Edad Media, hay un antes y un después en su composición y diseño con la aparición de la pólvora y los diferentes armamentos que la empleaban, desde los más ligeros y de uso personal a los más pesados necesitados de un amplio equipo artillero. Se considera que las trasformaciones efectuadas a lo largo del siglo XV suponen una etapa de transición entre los castillos de la Alta Edad Media (Cooper, 2012, p. 100; Mora 2002, p. 651), donde las defensas estaban pensadas para resistir el ataque de maquinaria de guerra, como arietes y torres de asalto, empleadas desde la Antigüedad, y las fortificaciones abaluartas del Renacimiento, diseñadas casi exclusivamente para el uso defensivo y ofensivo de la artillería.

Ya señalamos en el trabajo que anterior (Simón, et al. 2017), que el empleo de la pólvora está considerado como la primera de las revoluciones dentro del «arte de la guerra»

Su uso cambió las estrategias defensivas y ofensivas, el armamento y por consiguiente sus efectos tanto sobre los contendientes como sobre las estructuras que hasta ese momento se habían empleado. Existe un debate sobre su introducción en las tierras peninsulares, en las acciones bélicas que en 1331 desarrollaron las fuerzas de Mohamed IV de Granada en Alicante, bajo el reinado de Alfonso IV de Aragón (SOUSA, 1990, p. 98), y el sitio de Tarifa en 1340 por los benimerines, los cuales al levantar el sitio por la llegada de Alfonso XI de Castilla y ser derrotados en la batalla del Salado (1340) abandonaron su artillería, la cual paso a formar parte del equipamiento cristiano, usándola en el sitio de Algeciras de 13421344 , tanto por el rey castellano como por los defensores. 
Et otrosí muchas pellas de fierro que les lanzaban con truenos, de que los omnes habían muy grand espanto, ça en cualquier miembro del ome que diese, levábalo a cercén, como si ge lo cortasen con et tirabantes muchas piedras con los engeños, et concabritas, et otrosí muchas pellas de fierro que les lanzaban con truenos, de que los omes avian muy grand espanto, ca en qualquier miembro del ome que diese, levábalo cercen, como si ge lo cortasen con cochiello et quanto quiera poco que orne fuese ferido della, luego era muerto, et non avia cerurgia ninguna que le podiese aprovechar: lo uno porque venia ardiendo como fuego, et lo otro porque los polvos con que la lanzaban eran de tal natura, que qualquier llaga que ficiesen, luego era elome muerto; et venia tan recia, que pasaba un ome con todas sus armas ${ }^{1}$. (Arantegui, 1887).

A partir de ese momento se generalizó por todos los reinos cristianos peninsulares, lo que conllevó la necesidad de modificar los diseños de las defensas, como castillos y torres, la composición de los cuerpos de ejército y las estrategias de sitio.

La aplicación inicial se ciñó a piezas rudimentarias, denominadas «truenos» o «bombardas», que pronto dieron pasó a armas individuales, o 'truenos de mano', de menor diámetro y peso, que, por sus características, especialmente la lentitud e imprecisión, frente al arco y la ballesta, hizo necesario crear cuerpos mixtos de scopettieri y ballesteros, cuyas armas de fuego evolucionarán desde el arcabuz al mosquete. En su mayoría eran piezas de hierro forjado y eran parte del equipamiento de los ejércitos, tanto del rey como de los más importantes nobles, los cuales se aseguraban de disponer de los medios y los recursos para su elaboración y uso, dándoles una ventaja militar que les permitía imponer sus intereses, incluso a la propia corona.

Para el servicio de cada pieza artillera eran necesarios no menos de cuatro hombres que debían de tener una complexión «robusta y gallarda» y al menos uno de ellos debía de ser experto en

\footnotetext{
${ }^{1}$ Crónica del Rey D Alfonso el Onceno, (cap. CCXCII).
} 
la fabricación y uso de la pólvora (González, 1997, p. 373). Para su transporte eran necesarias caravanas o «trenes» tirados por caballos o bueyes, que tenían que ir precedidas por grupos de peones con un maestro al frente para ir reparando o reforzando los caminos, puentes o vados.

Sin embargo, disponer de artillería, tanto para los ejércitos reales como señoriales, era extremadamente costoso, pero sumamente intimidatorio, no tanto por su efectividad, tal y como se verá en la Guerra del Marquesado (1475-1480) (Pretel, 2002, p. 118), sino por su valor simbólico. La situación cambia radicalmente a partir del siguiente conflicto militar peninsular, la conquista del reino de Granada (1482-1492), que es definido por numerosos autores como la «conquista de la artillería» (Castillo, 2004, p. 42).

Entre 2009 y 2010 se realizaron actuaciones arqueológicas en el interior del Castillo de Chinchilla, como paso previo a la redacción de un proyecto de restauración y rehabilitación de la fortaleza, que permitieron localizar las dos piezas objeto de este trabajo, de las que apenas se da noticia al presentar los resultados de los trabajos arqueológicos (Izquierdo, 2011, p. 169-203). Tan solo se señala que, junto a las escaleras de la Puerta de la Villa, por su parte interior, se localizó «un cañón tipo bombarda (característico del S. XV), exhumado frente a las escaleras, al que se sumó la aparición de munición en piedra» (Izquierdo, 2011, p. 169-203), sin que podamos precisar si se trata de la bombarda o mortero o de la caña de bombarda, pues nada se precisa al respecto, al tiempo que falta cualquier información sobre la procedencia del segundo ejemplar.

Lo cierto es que ambas piezas son las únicas conservadas de la dotación artillera que la fortaleza contó en el siglo XV, relacionada con los acontecimientos bélicos de la Guerra del Marquesado, cuando fue sitiada y estas piezas, junto con otras que se han perdido, entraron en acción.

Tras la excavación se trasladaron para su depósito al Museo Provincial de Albacete, donde permanecieron hasta su traslado al Centro de Interpretación del Castillo de Chinchilla, emplazado en el 
antiguo Pósito, donde se exhiben y forman parte del material museográfico relativo a la historia del castillo de la localidad ${ }^{2}$.

Aunque las piezas objeto del presente estudio no son una novedad dentro del panorama de piezas artilleras de la época de los Reyes Católicos y poseen magníficos paralelos especialmente en el Museo de Artillería de Segovia y en el Museo del Ejército de Toledo, su interés resulta indudable, por lo que creemos necesario su estudio y difusión. Son las únicas existentes en Castilla-La Mancha, junto a las piezas del Museo del Ejército de Toledo, teniendo el interés de proceder de excavaciones arqueológicas y conservarse en la actualidad en su ubicación original, el Castillo de Chinchilla, a diferencia de otros conjuntos, como los cañones aparecidos en las excavaciones de La Mota de Medina del Campo en 1917, 1930 y 1939 que se perdieron y no han podido ser recuperados (Cobos y de Castro, 2000, p. 259).

\section{EL ARMAMENTO DE SITIO EN LA GUERRA DEL MARQUESADO DE VILLENA (1476-1480)}

La dotación artillera del castillo de Chinchilla en el final del siglo XV la podemos conocer a través de los trabajos de investigación que diversos autores han venido realizando sobre los acontecimientos acaecidos en el marco de lo que se viene denominando la Guerra del Marquesado (Pretel, 1987, 1992 y 2002; Ortuño, 2005), entre don Diego López Pacheco, II marqués de Villena y los Reyes Católicos, en el marco de la guerra de sucesión por la Corona de Castilla.

\footnotetext{
${ }^{2}$ Queremos agradecer al personal del Centro de Interpretación del Castillo de Chinchilla las facilidades para el estudio de las piezas. La toma de datos se tuvo que hacer sin manipularlas en ningún momento, ya que se encuentran sin restaurar y en un proceso de degradación muy severo, que hace temer por su integridad. Salvo las piezas que forman parte del Museo del Ejército de Toledo, son los dos únicos ejemplares de artillería medieval de Castilla-La Mancha y sería conveniente su tratamiento urgente.
} 
El conflicto sucesorio se dirimió en el control de las villa y castillos del marquesado de Villena, enfrentando de forma muy enconada a los partidarios de ambos bandos, lo que supuso el sitio y asedio de castillos como los de Chinchilla, Sax, Villena y Almansa y escaramuzas menores en Jumilla, Jorquera, Alarcón e Iniesta.

Según Ortuño (2005, p. 50), la dotación de efectivos humanos del castillo de Chinchilla estaría entre veinte o treinta individuos, los cuales contaban con un armamento propiedad del marqués, tanto los elementos de protección personal, como el armamento individual, la maquinaría mecánica y, sobre todo, las armas de pólvora, entre la que estaban las armas personales y veinticuatro piezas artilleras (Castro y Mateo, 2018, p. 115).

En el inventario de 1477, es decir, después de iniciarse el conflicto y tras finalizar el primer cerco a la fortaleza, que se extendió desde junio de 1476 a enero de 1477, se señala como piezas destacadas «cuatro lombardas gruesas y tres sin especificar, situadas en la torre del homenaje, en al baluarte de la puerta falsa o trasera y en la principal», que por su posición las podemos considerar como las armas de mayor calibre y alcance, defendiendo los puntos vulnerables del castillo, las puertas de acceso, tanto la de la «Villa», como la del «Campo» y pasando a la ofensiva desde el punto más alto de la Torre del Homenaje, desde donde se logra alcanzar mayor distancia y precisión, ya sea en un tiro curvo o un disparo recto o tenso, al tiempo que se está fuera del alcance de los sitiadores. Las piezas más destacadas descritas en ese inventario son:

- «Mas vna lonbarda gruesa con su seruidor».

- «Mas otra lonbarda gruesa con dos seruidores e su curueña e ocho faxas».

- «Mas otra lonbarda gruesa con su seruidor e su curueña e syete faxas e media, e vn trascoçe de faxa e tres çinchos e çinco perlos con sus chanetas».

- «Mas otra lonbarda gruesa con su seruidor e con su curueña e siete faxas e syete çinchos chanetas e vna rostra con su trascoçe e sus puntos». 
- «Mas otra lonbarda con dos seruidores e su curueña e nueue faxas, las syete con sus peros e chanetas e su trascoçe de fierro con sus cadenas».

- «Mas otra lonbarda con dos seruidores e con su curueña e con seys faxas e seys çinchos e vn trascoçe de faxa e su coge llana».

- «Mas otra lonbarda con dos seruidores e syete faxas, las çinco con perlos e chanetas e vn trascoçe de faxa e su coge con dos cadenas».

La efectividad de estas bombardas, o lombardas, les permite tener al alcance la Iglesia de El Salvador o San Salvador de Chinchilla, hoy San Julián, lo cual supone un alcance de 160 metros, con la pendiente a favor, lo que implica que toda la ciudad de Chinchilla estaba a su alcance ${ }^{3}$. Por el contrario, las dos bombardas empleadas por los sitiadores tuvieron que emplazarse en el Cerro de San Blas, a unos $170 \mathrm{~m}$., en unas atalayas y torres improvisadas, dado su tiro recto, y un trabuco, de tiro curvo, en el campanario de la Iglesia de San Salvador ${ }^{4}$. Este intercambio artillero, entre sitiados y sitiadores, supuso la destrucción del caserío en la parte alta, incluida la Iglesia de San Salvador (Fig. 1).

\footnotetext{
${ }^{3}$ Todo el caserío se encuentra a un alcance de $600 \mathrm{~m}$. quedando la parte antigua a una distancia de 330 a $400 \mathrm{~m}$.

${ }^{4}$ La Iglesia de El Salvador o San Salvador es lo que hoy se conoce como Iglesia y Hospital de San Julián (Pretel, 1992, p. 42).
} 

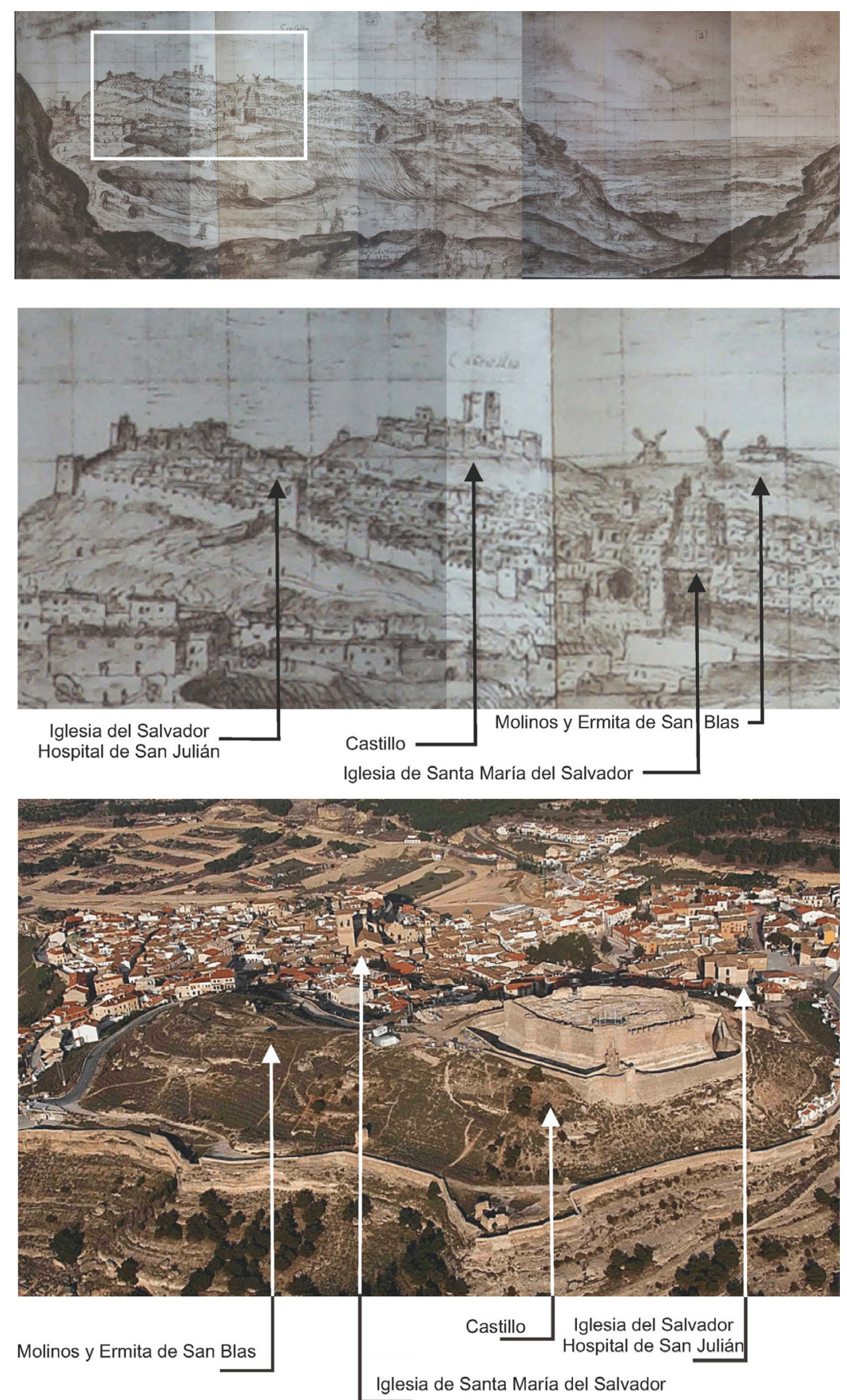

Fig. 1.- Los principales edificios implicados en el sitio artillero de Chinchilla, ubicados en el grabado de Anton van den Wyngaerderden de 1563. Detalle de la zona de conflicto en torno a la fortaleza y emplazamiento sobre una vista aérea actual. 
La singularidad de las «cuatro lombardas gruesas», conlleva la costumbre de la época de tener un nombre individualizado, que aparece en el inventario de 1480. Son la Osoria, la cual posee «dos servidores», es decir, dos recámaras, la Chinchilla, la Villena y la Marquesa, las tres con un solo servidor o recamara. Pudiera deducirse que la Osoria pudo ser de mayor tamaño y calibre y todas hacen alusión a lugares destacados del marquesado.

Seguidamente se relacionan los pasavolantes, unas lombardas de menor calibre, unos $20 \mathrm{~cm}$ y de unos $2 \mathrm{~m}$ de longitud (Ortuño, 2005, pp.58-59), dos de ellos completos, uno montado sobre una cureña fija y el otro sobre una escalera que permitía variar el ángulo de tiro, dos completas al parecer sin cureña y otras dos sin recámaras, por lo que se entiende que servirían de repuesto.

- «Mas un pasabolante con vn seuidor e vn escalera sobre que tyra».

- «Mas otro pasabolante con su curueña con çinco faxas con su rostra e çinco peros e su coge de cadena».

- «Mas dos medios pasabolantes, cada vno de ellos con su seruidor».

- «Mas otros dos medios pasabolantes syn seruidores».

Luego aparecen dos espingardones y cinco espingardas, unos cañones de manejo personal, usados con ayuda de una barra de apoyo de diferentes calibres y una espingarda de azofar inutilizada.

- «Mas çinco espingardas de llaue, cada vna con dos seruidores, e su coges con sus cadenas».

- «Mas vn espingardon».

- «Mas otro espingardon quebrado».

- «Mas otra espingarda de açofar quebrada».

Finalmente aparece un trueno y dos cuartazgo, que corresponderían a una bombarda trabuquera o un mortero o pedrero, de 
tiro curvo, dispuestos en cureñas fijas. Se señala que el trueno no posee la cureña, o al menos no se encuentra montado, por lo que pudiera estar inutilizado.

- «Mas un trueno desguarneçido».

- «Mas vn quartadgo grueso con quatro aldavas».

- «Mas otro quartadgo grueso con dos aldavas».

A todo ello habría se sumar los proyectiles, de piedra o hierro, adaptados a los calibres de cada una de las piezas, por lo que solían realizarse en el lugar y el momento de ser necesarios, para lo cual se contaba con los instrumentos de cantería adecuados, como calibres y plantillas de madera. Se señala la existencia de carretas herradas para mover las piezas de artillería más pesadas y desplazarlas al punto de la fortaleza más adecuado en cada momento.

- «Mas vna carreta de vna 1 onbarda e esta ferrada».

- «Mas otra carreta ferrada, que es de otra lonbarda».

- «Mas otra carreta ferrada de otra lonbarda».

- «Mas otra carreta de pasabolante».

- «Mas otro carreton de vn pasabolante ferrado».

- «Mas dos exes de olmo de las carretas».

- «Mas vna rostra de vna curueña de otra lonbarda».

- «Mas dos moledores de polvora».

- «Mas vn cargador de fierro de las lonbardas de dos garavatas».

Finalmente se indica que la pólvora, la cual se realizaba en la propia fortaleza y para ello contaba con los instrumentos necesarios, como morteros y cedazos, sacas de tela, etc., se guardaba en una estancia concreta «la casa del bastimento de la pólvora» mientras el salitre para realizarla estaba en la planta baja de la torre del Homenaje, la cual contaba con una cubierta en bóveda, tal y como se aprecia en el plano de Josef La Corte de 1811 (Simón, 2011, p. 141). Su emplazamiento queda reflejado en el inventario de 1480 
(Ortuño, 2005, p. 131), donde se señala que en la «troxa de la casa del bastimento» hay...

- «Mas de plomo seys arrobas e diez e nueve libras».

- «Mas siete arrobas e catroze libras de poluora en quatro çurrones».

- «Mas dos arrobas de cañamo en çerda».

- «Mas vn trueno pequeño quebrado».

- «Mas de salitre veynte e siete arrobas e veynte libras, pesese en seis pesos con vna talega. No se quitaron las taras».

- «Mas de çufre catorze arrobas e quatro libras. Pesese en dos pesos con la talega. No se tyro la tara».

En 1480, tras el fin de la contienda entre el marqués y la Corona, se había logrado reunir en la fortaleza chinchillana la impresionante cifra de cuarenta piezas, con este desglose: once lombardas, tres medias lombardas, cinco pasavolantes, tres medios pasavolantes, cuatro cerbatanas, un trueno, cuatro cuartagos, siete espingardas de llave, un espingardón y una espingarda de azofar. En la Torre del Homenaje se inventariaron:

- «Mas vn pasabolante en la torre del omenaje en curenado en su banco e puntos con su seruidor».

- «Mas vna curaena de madera de media lonbarda syn fyerro ninguno».

- «Mas vna lonbarda gruesa encuruñada con dos çinchos e otro jincho delgado a la coz!».

- «Mas vn quartadzgo grueso con sus quatro hebillas».

- «Mas en el baluarte de la puerta falsa media lonbarda con su seruidor, el quaj esta dentro en la fortaleza».

- «Mas otra lonbarda desencureñada que esta quitado vn çello a do se junta el seruidor».

- «Mas otra lonbarda gruesa desencurenada con su seruidor». 
- «Mas otra media lonbarda larga con su seruidor».

- «Mas vna curena de media Ionbarda con vn perno e dos clavos largos con su ençerado grande con dos hevillas».

- «Mas vn pasabotante con su seruidor».

- «Mas otra lonbarda guresa con su seruidor».

- «Mas otro quartadzgo grande».

- «Mas otra lonbarda gruesa con su seruidor e tres piedras grandes con ella desencurenada, vn cauallete de ella de madera con su apuntador de fierro e sus hebillas».

- «Mas otra lonbarda gruesa con dos seruidores desencurenada».

- «Mas otra media lonbarda larga con dos seruidores».

Mientras que en el Palaçio Grande, el inventario recoge:

- «otra curaena grande vieja de lonbarda con dos faxas».

- «Mas vn espyngarda de llaue con su curena».

- «Mas vn espingarda rebentada».

- «Mas vn espingarda encurenado».

- «Mas vn espyngarda desencurenada».

- «Mas vn çedaço de pasar poluora».

- «Mas dos moledores de palo de moler poluoral».

- «Mas otra espyngarda rebentada ».

- «Mas otra espyngarda desencurenada».

- «Mas otras dos espyngardas encurunadas [sic] e con su barrena e tacadores».

- «Mas quatro seruidores de espyngardas de llaue».

- «Mas otro seruidor de espyngarda con llaue».

- «Mas otro molde para fazer piedras de lonbardas con dos asas».

- «Mas dos medios pasabolantes syn seruidores».

- «Mas vna maroma grande del trabuco de cañamo».

- «Mas otro pedaço de maroma de cañamo del dicho trabuco».

- «Mas vna honda de cañamo del dicho trabuco». 
- «Mas otro seruidor de llaue pequeño».

- «Mas çinco curaenas de espingardas de Ilaue».

- «Mas vna coge grande de fierro de lonbardas con sus cadenas».

- «Mas vn trascoçe de fierro grande con su cadena».

- «Mas otra coz de fierro grande de lonbarda con su cadena».

- «Mas baxo de la trox fasta veynte arrobas de caruon de pyno e de sajes para poluora».

- «Mas al cabo de la casa el bastymento fasta quinze arrobas de carbon de carrasca porque ay deçisco, e tierra otras quinze arrobas».

- «Mas otro çedaço de pasar poluora.»

Este conjunto artillero es completamente engañoso, ya que su estado era muy deficiente, tal y como queda reflejado en el inventario de 1480, donde aparecen muchas piezas «desencureñadas», «reventada» o «ronpidos», seguramente porque las mejores, o al menos las que todavía tenían un cierto uso y valor, tras la capitulación con los Reyes Católicos (Franco, 2005) fueron, junto con las de otras fortalezas del marqués, desplazadas a un lugar seguro, para luego ser empleadas en otras campañas, como la conquista del reino nazarí de Granada o las campañas de Carlos V en Flandes, tal y como queda reflejado en su testamento (Ortuño, 2005, p. 58).

De todo este conjunto, en los trabajos de excavación efectuados entre 2009 y 2010 se recuperaron una bombarda o mortero, y una caña de bombarda que, por su longitud -de unos $2 \mathrm{~m}$ con la recamara- sería un pasavolante de munición en piedra y hierro, como bolaños de diferente calibre y pelotas de hierro. Una de las piezas apareció en la parte interior de la puerta de la Villa, tal y como se señala en la documentación histórica, pero no se especifica en el trabajo de Izquierdo (2011) cuál de las dos piezas recuperas en las excavaciones corresponde con tal procedencia. 


\section{LA BOMBARDA TRABUQUERA, MORTERO O PEDRERO DEL CASTILLO DE CHINCHILLA}

La falta de homogeneidad en la artillería primigenia lleva en ocasiones a utilizar la misma terminología para piezas semejantes en composición, pero muy diferentes en su uso, pese a que su finalidad es la misma, lanzar proyectiles al enemigo con el fin de causar el mayor daño posible. De ahí que encontremos el término bombardas o lombardas para referirse en ocasiones a lo que con posterioridad se denominarán morteros o pedreros (Herrero, 2004, p. 167). En este caso se trata de una pieza artillera compuesta por un solo elemento realizado a partir de láminas de hierro, que posee dos secciones, una de menor tamaño que hace las funciones de recámara y otra más amplia que es la cámara o tubo, muy corto, donde se aloja el bolaño o proyectil. Sirven para efectuar tiros curvos, bien para superar las defensas exteriores, atacando el interior del recinto defensivo, o para emplazamientos a una cota mayor que las de los sitiadores. Un ejemplo de este tipo de uso en posiciones elevadas fue su utilización en el sito de Ronda (1485) y posteriormente en el de Málaga, en concreto contra la fortaleza de Gibralfaro (1487) (Gil y Toledo, 2008, p. 319). 

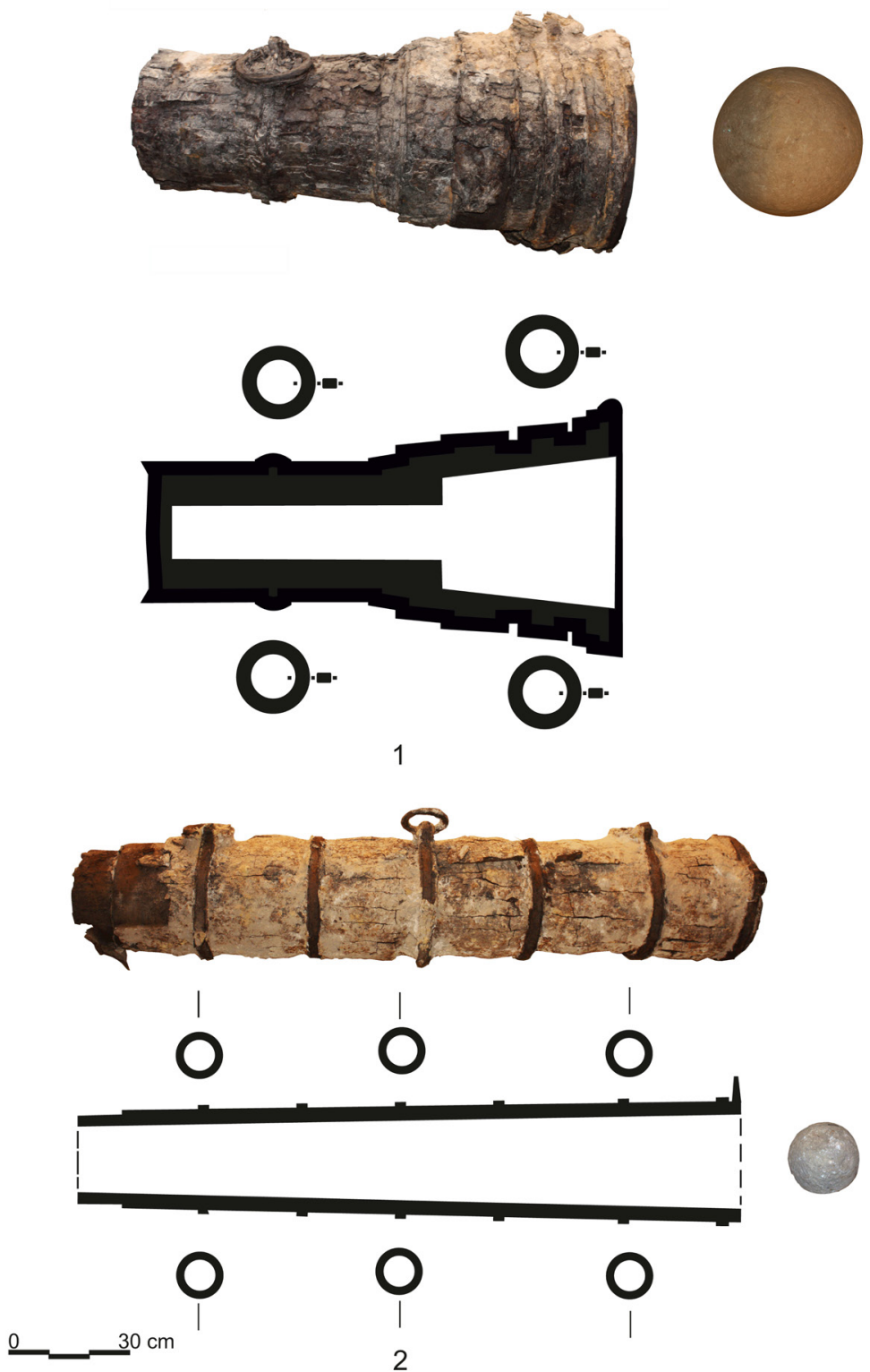

2

Fig. 2.- 1. Bombarda trabuquera o mortero 2. Caña de bombarda. Bolaños.

La pieza no 1 (Fig, 2.1) está completamente oxidada en la actualidad y en un estado de corrosión muy avanzado, pero todo indica que se encuentra completa. Posee una longitud total de $102 \mathrm{~cm}$, de los cuales $49 \mathrm{~cm}$ son de la recámara y el resto, $53 \mathrm{~cm}$, del tubo. Al 
exterior la pieza se refuerza en la cámara con un aro o duela de hierro que a su vez sirve para sujetar dos anillas, a ambos lados, que se conservan adheridas y oxidadas y tienen como misión poder modificar el ángulo de tiro al tiempo que sujetar la pieza en la cureña. El tubo presenta igualmente dos aros o duelas de hierro para reforzar su resistencia, conservando en el más próximo a la boca dos anillas de hierro, de sección cuadrangular con las esquinas redondeadas, lo que se relaciona con el proceso de forja. Se conserva el punto de mira, justo en el borde a modo de resalte redondeado y no hemos podido localizar por el grado de oxidación el oído o fogón. La parte interior se conserva vacía, lo que permite conocer sus dimensiones, la cámara posee $60 \mathrm{~cm}$ de profundidad por $20 \mathrm{~cm}$ de diámetro y la caña $38 \mathrm{~cm}$ de profundidad por $52 \mathrm{~cm}$ de diámetro, lo cual nos da la media de los bolaños de piedra y por tanto su calibre y peso, ya sea en piedra o hierro, además de poder arrojar cestos de piedras, de donde toma el nombre de «pedrero» (Sousa, 1990).

Las argollas servirían para sujetarla a la cureña, habitualmente sin ruedas, y facilitar su manejo y traslado, al tiempo que permitir mediante poleas y cabrestantes modificar el ángulo de tiro. Una pieza similar está en la Sala de Armas del Alcázar de Segovia (Herrero, 2004, p. 170, fig. 8), donde se acompaña de los braseros para su accionamiento. La pieza de Chinchilla se menciona de forma genérica en los inventarios de 1477 y 1480, sin que se pueda precisar su emplazamiento concreto (Fig. 3). 

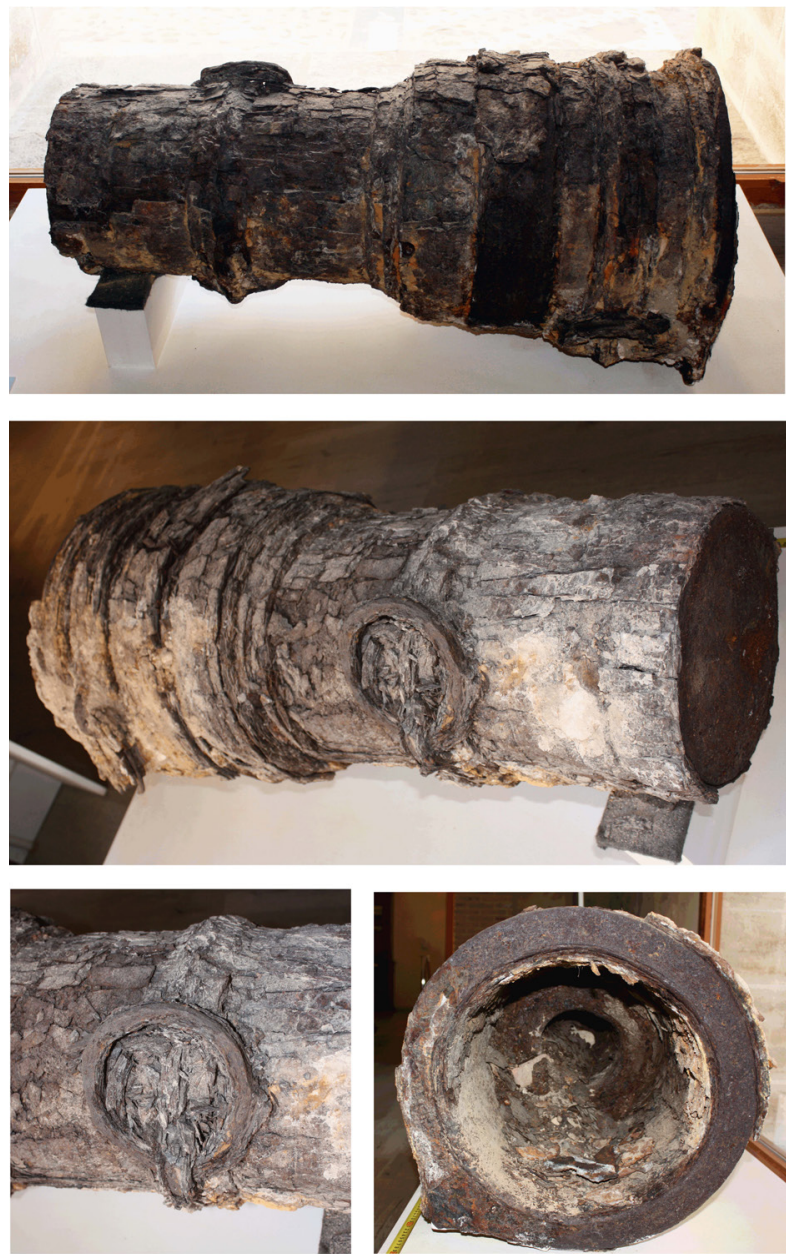

Fig. 3.- Detalles de la bombarda trabuquera o mortero del Castillo de Chinchilla

\section{LA BOMBARDA, LOMBARDA O CAÑA DE FUEGO DEL CASTILLO DE CHINCHILLA}

Las bombardas están compuestas de dos piezas, una de mayor longitud, la caña, que es la que recorre el proyectil para un disparo recto o tenso, y la recámara, mucho más corta, de menor calibre y, donde se coloca la pólvora, situada en la parte posterior. Ambas poseen anillas de refuerzo exterior, colocados en caliente para su unión con las barras de la caña, con la longitud y forma decididas mediante forja. Después se limaban los laterales y con ellas 
se completaba el tubo interior. En la parte posterior estaba situado el resalte para el enchufe de la recámara. Se construía con un aro en el interior de la parte posterior de la caña, que iba sujeta con los redobles de las barras interiores. Se finalizaba la construcción con las argollas y refuerzos. Cada bombarda tenía unos proyectiles determinados, por lo que se calculaba antes el calibre de cada una. Para construir la recámara, las barras se trabajaban de la misma manera que las de la caña. Para terminar, se soldaba el enchufe y se formaba la culata (López, 2011, pp. 241-242).

Una caña de bombarda podía ir dotada de varias recámaras y tanto la caña como la recámara debía quedar perfectamente unidas y sujetas a la cureña para efectuar un disparo con éxito ${ }^{5}$. La cantidad de pólvora se dejaba a criterio del artillero en las primeras épocas. Sin embargo, desde fines del siglo XV se acordó que la pólvora llenaría las tres quintas partes de la recámara, quedando una quinta parte sin llenar y otra quinta parte ocupada por un taco de madera de tilo, sauce o pino. Después la recámara se encajaba en la caña. El bolaño se introducía por la boca de la caña, empujándole hasta el fondo y acuñándole. Una vez hecho fuego, se sacaba la recámara. Esto podía efectuarse soltando las cuerdas, corriendo la pieza hacia adelante o retrasando el tope posterior (Sousa, 1990).

La pieza $\mathrm{n}$ - 2 o bombarda de Chinchilla solo conserva la caña (Fig. 2.2). En la actualidad posee una longitud de $162 \mathrm{~cm}$, un diámetro en el resalte de $22 \mathrm{~cm}$ y $10 \mathrm{~cm}$ de longitud, apreciándose una deformidad en las barras de hierro que pudiera indicar un estallido accidental. El resto de la caña lo conforma un tubo con seis aros o duelas de hierro de refuerzo, de 2,5 cm de ancho, a intervalos de entre 22 y $25 \mathrm{~cm}$. La boca tiene un diámetro exterior de $30 \mathrm{~cm}$ y 24 $\mathrm{cm}$ al interior, lo que da un espesor de las paredes de $3 \mathrm{~cm}$. Posee el punto de mira situado en el mismo borde, de forma redondeada. El calibre se situaría en los $24 \mathrm{~cm}$, tanto para bolaños de piedra como de hierro (Fig. 2.2).

\footnotetext{
${ }^{5}$ Algunos autores señalan que una bombarda podía realizar cuatro tiros por hora con un alcance de entre 1.300 a $2.000 \mathrm{~m}$, una distancia donde la precisión es muy escasa (Vigón, 1947).
} 
El deficiente estado de conservación y la diferente corrosión permiten apreciar las láminas de hierro longitudinal que configuran la caña. Posee un par de argollas en los aros o duelas de refuerzo de forma alternante, en tres de ellos, desde el resalte hacia la boca. En la actualidad la pieza esta rellena del sedimento que la cubría y es lo que le da consistencia a la caña (Fig. 4).
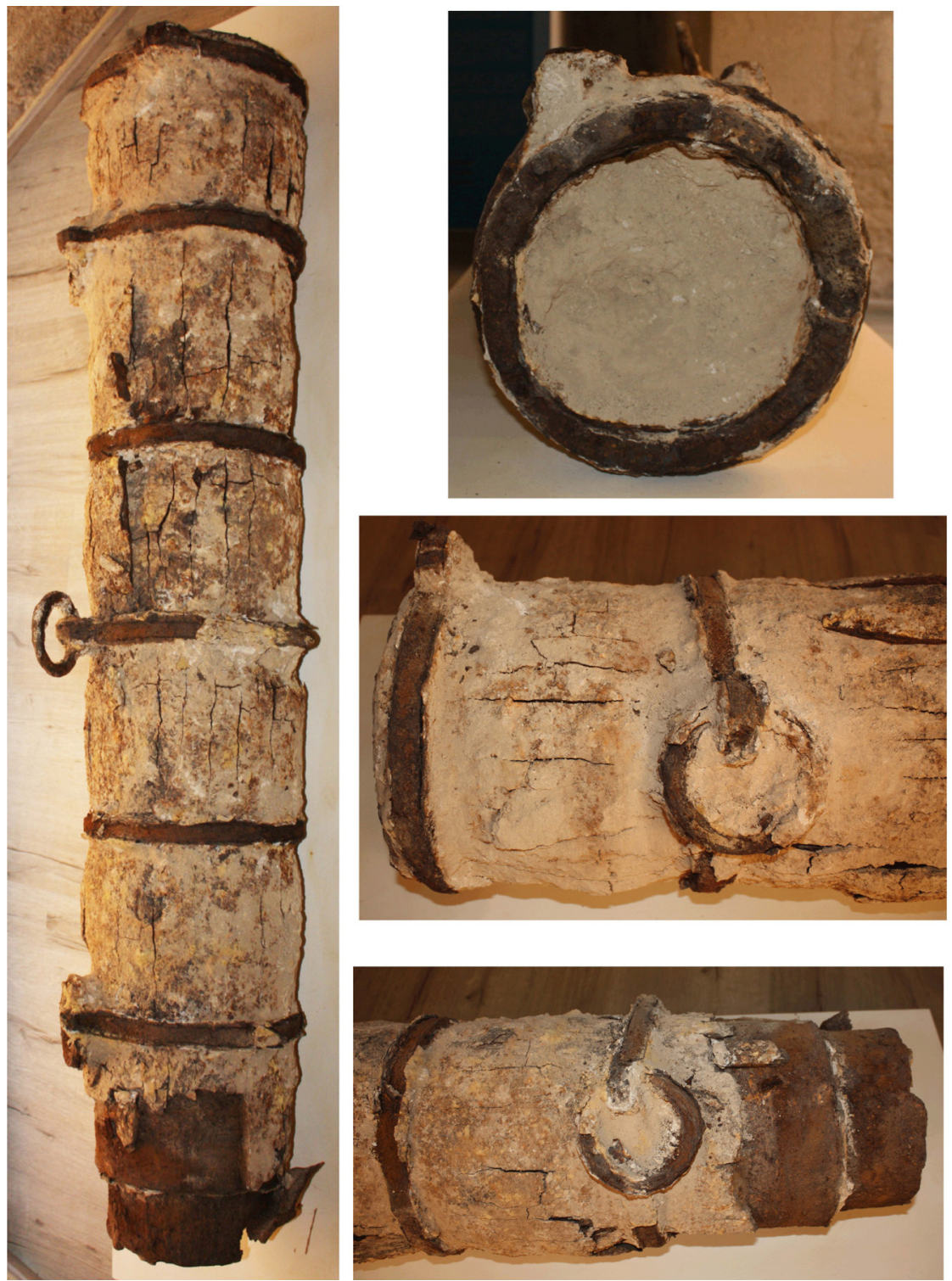

Fig. 4.- Detalles de la caña de bombarda del Castillo de Chinchilla 
Es un tipo de pieza muy común, ampliamente utilizada en el siglo XV, especialmente en su segunda mitad, siendo sustituida en el siglo XVI por los cañones de bronce. Es una de las piezas mencionadas en los inventarios de 1477 y 1480 , sin que se pueda precisar su emplazamiento y no creemos que por su tamaño tuviera una denominación singular.

El alcance máximo se estima en $1.300 \mathrm{~m}$, con una máxima efectividad entre los 100 y los $200 \mathrm{~m}$ en un tiro recto o tenso, muy útil para abrir brechas en los muros de defensa, y una cadencia de ocho disparos al día, La fatiga de materiales, y seguramente el uso incorrecto de la pólvora, hizo que muchas de ellas reventasen por la junta de unión entre la caña y la recámara, lo cual se puede apreciar en muchos de los ejemplares conservados y en parte en el aquí analizado.

\section{OTROS ARMAMENTOS DE FUEGO DEL CASTILLO DE CHINCHILLA}

Los proyectiles recuperados en la intervención, por su calibre y características, la mayoría 'pelotas' de hierro, debieron de ser usadas por falconetes, ribadoquines y sobre todo cerbatanas, que aparecen mencionadas en el inventario de 1480. De hierro se exponen 12 ejemplares de 5-6 cm de diámetro, 16 de 3-4 cm y 26 de 2-3 $\mathrm{cm}$, todos ellos con un intenso proceso de corrosión que distorsiona su tamaño y peso.

Los bolaños, realizados en piedra caliza, son de varios diámetros y pesos, por lo general medianos, entre 5 y 12 arrobas, y pequeños de 1 a 5 arrobas $^{6}$. En el Centro de interpretación hay expuestos siete, dos de tamaño mediano y cinco de tamaño pequeño.

Las balas de fuego, huecas, con carga explosiva interior, se usaron por primera vez en el sitio de Ronda de 1484 por la artillería de Fernando El Católico (González, 2003). En las excavaciones del castillo de Chinchilla se han recuperado unos proyectiles huecos, de

\footnotetext{
${ }^{6}$ Una arroba equivale a 11,339 kilogramos y a 25 libras.
} 
un calibre diferente al de los cañones de a 6 largo y de a 12 del siglo XIX (Simón, Lorrio, Sánchez y Moneo, 2017, p. 181) pero que requieren de un estudio detallado para determinar su cronología.

\section{LA ARTILLERÍA EN LAS FORTIFICACIONES DEL MARQUESADO DE VILLENA}

Cuando en 1445 el rey de Castilla y León, Juan II, otorga el título de marqués de Villena a don Juan Pacheco, lo hace sobre una serie de villas que habían pertenecido al antiguo señorío de Villena, aunque otras todavía estaban bajo la jurisdicción real o de otros señoríos, por lo que el primer objetivo del nuevo marqués será la recomposición del marquesado, un territorio que había sido un apanage de la monarquía reservado a los segundones de la familia real desfavorecidos por las leyes de herencia, lo que encumbraba a don Juan Pacheco en el escalafón de la época a los más altos puestos de la corte castellana.

El segundo objetivo era afianzar ante sus nuevos súbditos su poder, puesto que entre la concesión y la posesión real pasan en ocasiones años de disputas, litigios y resistencias de agraviados, alcaides y concejos. En tercer lugar, eran necesarias ante sus rivales y enemigos unas defensas capaces de repeler o servir de bases a las ofensivas militares. Este último aspecto, la importancia de los castillos y alcázares para cualquier maniobra política (Franco, 2012, p. 62) había sido la primera lección que había aprendido el marqués al servicio del entonces príncipe de Asturias y quizás fuese, entre otras muchas circunstancias, la principal causa del programa de reformas que emprendió en sus fortificaciones del marquesado casi al unísono, hasta el punto de que en muchas de ellas la fortaleza surgirá de forma casi ex novo.

Entre la posesión de los castillos del marquesado por don Juan Pacheco, que podemos fijar a partir de 1445, y la cesión a su hijo don Diego Pacheco en 1468, se desarrolla una actividad frenética de construcción que durara una veintena de años, que apenas 
tiene continuidad por el II marqués de Villena, finalizando en la mayoría de los casos con el inicio de la Guerra del Marquesado (14751480). Será un periodo muy breve de tiempo para tan importante objetivo, en el que será necesario un constante esfuerzo económico, fruto del cual será el aumento de la presión fiscal del marqués sobre sus vasallos y la denuncia por sus rivales de la apropiación de las rentas reales (Pretel, 1981, p. 109). Al mismo tiempo es necesario un importante esfuerzo organizativo, en donde participarán maestros de traza y obra asistidos por canteros para las partes singulares y simbólicas de los edificios, especialmente la sillería de puertas, ventanas, escaleras, arcos, claves, heráldica y epigrafía o los elementos defensivos como matacanes, ladroneras, troneras y elementos constructivos singulares. Serán necesarios alarifes especializados en obras hidráulicas, como pozos y aljibes y cuadrillas de peones para el resto de las fábricas de mampostería, junto con los maestros artilleros para el diseño y emplazamiento de las nuevas defensas que emplean la pólvora.

Por el momento son pocos los datos que se poseen sobre la participación de maestros de obras en la construcción de los castillos del marquesado y si estos participaron en la concepción general de los edificios o solo en su parte ornamental y simbólica. En algún caso se ha relacionado a Hanequin de Bruselas, que participo en la colegiata de San Bartolomé de Belmonte, con el proyecto y traza de castillo palacio de don Juan Pacheco en esa localidad, suponiendo la continuación de la construcción del castillo-palacio por el maestro de traza y obra Juan Guas, tanto por las similitudes con otros castillos-palacios, como el castillo de Manzanares y el de Mombeltrán, como la relación con el marqués en la construcción del monasterio del Parral de Segovia.

En la obra clásica Castillos Señoriales en la Corona de Castilla, Cooper (1991, p. 25) establecía una relación de diseño y edificación entre algunos de los castillos de Castilla, que entre los que nos ocupan estarían los de Belmonte (Fig. 15) y Mombeltrán (Cooper, 1991, p. 169) o la similitud entre las torres del homenaje de Belmonte y 
Jumilla (Cooper, 1991, p. 831), pero no señalaba que existiera una relación entre la mayoría de los castillos del marquesado de Villena. Sea como fuere, las obras en los castillos del marquesado se extienden por todo el territorio, desde las edificaciones de nueva planta, como Belmonte o Garcimuñóz, a los que sufrieron reformas sustanciales que podríamos considerar casi como edificaciones ex novo, como Villena, Almansa, Jumilla o Chinchilla, y los que fueron reforzados con elementos puntuales como Alarcón, Sax, Alcaraz, Tobarra, Hellín y quizás Requena. Los refuerzos de las construcciones preexistentes se extendieron a otros castillos bajo su posesión, especialmente en Escalona (Cooper, 1991, p. 714) y en otras muchas se afrontaron reparaciones y acondicionamientos sustanciales. A ellos se le sumarían los construidos por personajes relacionados con los Pacheco, ya sean como vasallos o aliados, como serían los casos de Carcelén, Jorquera y Alcalá del Júcar y posiblemente en castillos que han desaparecido, como Albacete, La Roda y Munera, ente otros (Simón, 2011). Finalmente, podríamos relacionar todo este esfuerzo edilicio con otras fortalezas, como algunas de las pertenecientes a la Orden de Santiago, de la cual será don Juan Pacheco su maestre a partir de 1467 y la de Calatrava (Franco, 2012, p. 305), que gobernaba en nombre de su sobrino, especialmente en las que rodean al marquesado en Cuenca, Toledo, Ciudad Real y Murcia.

Todos estos castillos se enmarcan en mayor o menor grado en lo que se conoce como Escuela de Valladolid, estilo de la segunda mitad del siglo XV, caracterizado por un recinto relativamente reducido, o torrejones compactos sin recinto anexo, con una torre del homenaje de amplia planta, gran elevación, emplazada habitualmente en una esquina de la fortaleza y rematada en ocasiones con escaragüitas, matacanes corridos y merlones piramidales. Se complementa el núcleo central con dos o tres recintos perimetrales, una plaza central y un acceso entre dos torres semicirculares, generalmente adelantado mediante una barbacana.

Sin embargo, el empleo de la artillería de sitio irá haciendo necesario la adopción de una serie de elementos de resistencia pa- 
siva, como dotar de alambores de entre $45^{\circ}$ y $60^{\circ}$ a lienzos de murallas y torres exteriores para favorecer el rebote de los proyectiles, potenciar la falsabraga o barrera y dotarla de cubetes y cubos con troneras que en una fase algo más tardía serán sustituidos por antepechos de remates abocelados, al tiempo que se reduce la altura de la fortaleza y en especial la de las torres del homenaje, lo que supondrá la necesidad de aumentar la altura desde la base de las barreras exteriores mediante fosos, que al mismo tiempo supondrán una dificultad añadida a los intentos de realizar minas desde donde emplear la pólvora para causar el derrumbe de murallas y baluartes (Mora, 2002, p. 552).

Cuando don Juan Pacheco ordena la reforma, adaptación o construcción de las fortalezas del marquesado se hará siguiendo las pautas del momento y por lo tanto las necesidades surgidas del empleo de la artillería, los contingentes militares y las tareas de control, recaudación fiscal y mantenimiento del sistema señorial, a lo que se le sumará toda la simbología que para ello era necesaria, siendo una de las últimas manifestaciones de un estado señorial que dará páso a la monarquía autoritaria de los Reyes Católicos y los nuevos modos de gobierno de la Edad Moderna (Petrel, 2011, p. 467).

La transformación no solo fue del edificio, sino que alcanzó a su equipamiento armamentístico, tanto individual como colectivo, donde la artillería jugaba un papel predominante, y a los especialistas necesarios para su manejo. Por desgracia no contamos con inventarios de traspaso de alcaidía o inventario de todos los castillos del marquesado, pero un repaso a algunos de ellos nos puede dar una idea del panorama general (Fig, 5). 


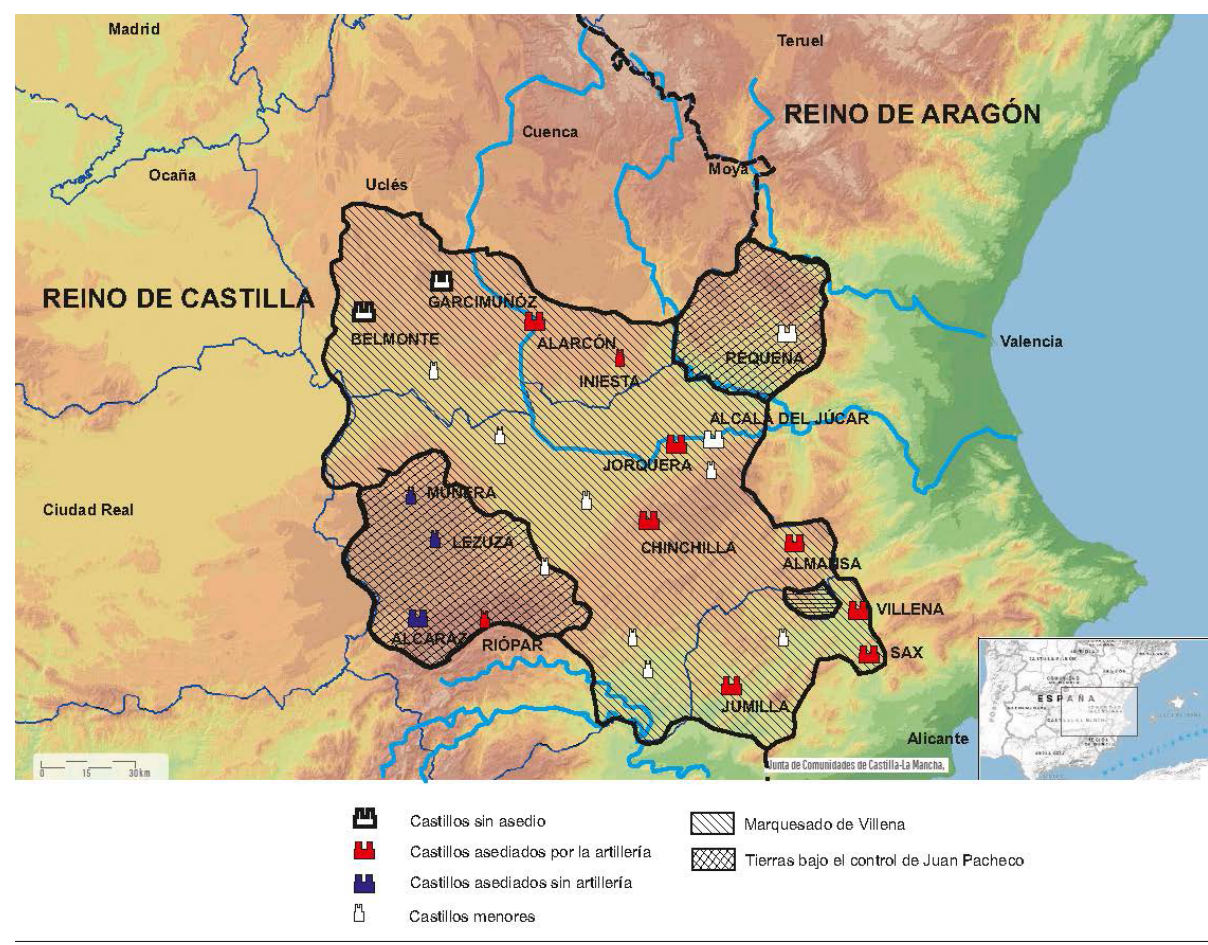

Fig. 5.- Mapa del marquesado de Villena con indicación de las fortalezas sitiadas por la artillería.

En el Casillo de Sax se han identificado como obras de don Juan Pacheco el abaluartado de la muralla exterior por el lado del acceso, la puerta principal defendida por dos torres semicirculares a ambos lados y el refuerzo del aljibe donde actualmente se aloja el único escudo que se conserva del Marques de Villena, si bien se tienen dudas sobre si este fue su emplazamiento original. Igualmente, la reforma de la última planta de la torre del homenaje tras el conflicto con los Reyes Católicos pudo ser la causa de la desaparición de la heráldica señorial, al haber pasado la fortaleza al dominio real tras la capitulación del marqués (Simón y Segura 2002, pp. 26-31).

Como equipamiento de pólvora sabemos que el castillo contaba, por el inventario de 1478, realizado por la toma de posesión el 15 de noviembre de 1478, por Joan Roiç de Corella y Moncada, III conde de Cocentaina, siendo alcaide del castillo su hermano Perot 
Roiç de Corella, del siguiente armamento, documentado en diferentes estancias del castillo (Ochoa, 2018).

- «Cuatro Spingardes de ferre ab sos azbrers e enbotidors».

- «Una Arrova de polvora».

- «Una Bombarda de ferre, apellada La Duquesa, ab son cep e 2 servidors».

- «Una Carabatana de ferre, ab 1 camissa rompuda, sens servidors, desencavalcada».

- «Una Carabatana de ferre ab son cep, cavallt e forqueta de ferre ab son piu».

Bajo la tenencia de Joan Roiç de Corella y Moncada, III conde de Cocentaina, se efectúa en mayo de 1492 la permuta de alcaidias de Sax y Salinas, entre Juan Luis de Fluvia, alcaide del castillo de Sax representado por su hijo Luis de Fluvia, que es sustituido por Juan de Pamplona, alcaide de la Torre de Salinas, pasando el primero a desempeñar el alcaidato de esta última. El notario Guillén Periz, acompañado de Juan de Anglesola, Baile (Administrador Real) de Aspe, como procurador del conde, y Damian Juneda, Alcaide de Petre. Juan Navarro, justicia del lugar de Salinas y Pedro Lazer, peraire (cardador de lana) de Cocentaina, como testigos, realizan un inventario de los objetos de la fortaleza sajeña, donde se señala la presencia de (Sáez, 1982, p. 75):

- «Dos carabatanes con sus servidores y un soporte, buenas y casi nuevas.»

- «Una bombarda mediana llamada la Cocentaina.»

- «Otra bombarda (quizás La Duquesa).»

- «Dos espingardas con unos grilletes.»

- «Otra bombarda pequeña, todas con sus servidores.»

- «Culebrina de fuego.»

- «Una carabatana.»

- «Dos espingardas.» 
Del sitio artillero se conservan los impactos en la torre del homenaje, orientados hacia los ángulos con el fin de provocar su derribo y algunos en las fachadas oriental y meridional. Su diámetro oscila entre los 10 y los $25 \mathrm{~cm}$ de diámetro, por lo que parece que son alcances de bombardas de reducido tamaño, fáciles de transportar y emplazar en la creta rocosa del cerro del castillo o de espingargas o cerbatanas. Lo cierto que el bombardeo al parecer tenía poca efectividad, salvo la psicológica, pero el convencimiento del alcaide de que no recibiría ayuda exterior de su señor el marqués y la apertura de una brecha en la muralla por la acción aislada de un soldado del conde de Cocentaina, de origen vizcaíno, llevó a la capitulación de la fortaleza, con un buen trato al alcaide que de ese modo cambiaba de bando (Simón, 2010, p. 75).

El Castillo de Villena fue reformado en profundidad al igual que casi la totalidad del resto de fortalezas del marquesado. Se dotó a la torre del homenaje de dos cuerpos con escaragüitas en las esquinas, con los correspondientes escudos heráldicos, se cerró el recinto interior con torres circulares en las esquinas, mientras que al exterior se dotó de torres circulares las esquinas y una barbacana que incluía una noria y protegía el flanco de la torre del homenaje respecto al caserío de la villa. En los dos recintos se instalaron troneras de palo y cruz con orbe, que por su calibre son para armas de fuego personales del tipo falconete, cerbatana y ribaldoquín, pudiendo alojarse las piezas de mayor calibre en la terraza de la torre del homenaje, como en el caso de Jumilla, o en la barbacana.

El castillo debió contar con armas de fuego, como una bombarda o lombarda con caballete de madera con su apuntador de hierro y sus hebillas, que permitían sujetarla a la «cureña gruesa con seis faxas e cinco cinchos e cuatro chavetas e cadenas en ellas e seis pernos que la atraviesan con su sortija a la coz» (Castro de y Mateo, 2018, p. 114). Según Cooper el marqués don Juan Pacheco tuvo a intención de montar una fundición de artillería en esta plaza, al igual que la existente en la fortaleza de Moya, la cual era abastecida por los pinares de la zona, pero al parecer nunca llegó a realizarse (Cooper, 1991, p. 869). 
Sin embargo, los hechos acontecidos y relatados del conflicto civil en Villena indican que los enfrentamientos y combates se dieron de forma principal en el caserío, refugiándose los partidarios del marqués en la fortaleza, sufriendo la pérdida de la vida y los bienes aquellos que no la alcanzaron, tal y como señala Ortuño (2005, p. 47), hasta el punto de que tras las hostilidades los monarcas tuvieron que otorgar un perdón general a aquellos que habían participado en las matanzas.

La fortaleza fue objeto de sitio entre enero y julio de 1476, sin que por el momento sepamos las circunstancias bélicas, pero tal y como había ocurrido en otros castillos del marquesado, como Sax y Chinchilla, pudo utilizarse alguna pieza de artillería de sitio, tal y como se aprecia en los impactos que tanto la torre del homenaje, como el recinto exterior, unos pertenecientes a este conflicto, seguramente los de mayor tamaño y calibre, con una corona de astillado en el impacto muy definida, seguramente por el uso de bolaños de piedra, frente a otros de mucho menor calibre y una corona de impacto muy irregular, fruto del impacto de proyectiles de hierro de menor calibre que al impactar estallaban a modo de metralla ${ }^{7}$.

El alcaide, Pedro Pacheco, capituló, ante la falta de ayuda del marqués y el sitio del Baile de Elche, Gaspar Fabra que disponía además de los vecinos alzados contra el marqués de 40 caballeros y 300 peones, sin que se señale mayor detalle de la composición de la hueste, quizás porque el pago de sus salarios los asume directamente los monarcas o el propio Baile de Elche, tal y como figura en la capitulación del 20 de febrero de 1476 (Soler 1969, p. 105), frente a las reclamaciones de gastos que hicieron otros participantes, como el conde de Cocentaina, el cual detalla con minuciosidad los diferentes sueldos en función del cometido de cada participante en los sitios de Sax y Chinchilla (Sáez 1982, p. 590).

\footnotetext{
7 Otros impactos pueden deberse a conflictos posteriores, como la Guerra de Sucesión, cuando el castillo es sitiado entre el 18 y 24 de febrero de 1707 por tropas austracistas, o la Guerra de la Independencia, cuando se sitia la fortaleza en 1813 por tropas francesas. (Arnedo, 2013).
} 
En el Castillo de Jumilla las reformas en la fortaleza islámica son radicales, se derriba casi en su totalidad el alcázar musulmán y se sustituye por un castillo compuesto por una gran torre del homenaje de cinco plantas, esquinas redondeadas, refuerzo semicircular en la pared que da al exterior, un recinto amurallado, una parte de él son los aljibes y un tramo de lienzo con una torre cuadrada y una barbacana con un puerta principal flanqueada por torres circulares, donde se emplazan buzones y troneras. Se crea una cámara artillera en el extremo sureste del recinto islámico y se dota al acceso del recinto militar de una pequeña torre pentagonal, a modo de revellín (Hernández y Simón, 2015, p. 107).

Se realiza un inventario tomando los datos aportados por Pedro Carrión Tomás de un acta del Concejo de 1564, donde se señala que en ese año en la terraza de la torre existe un «falconete con cureña con dos servidores o recámaras» y en el «patrio de armas... tres culebrinas pequeñas, tres bombardas de hierro y tres cañones para la defensa de la puerta del Castillo...». Pese a ser un inventario de casi ochenta años posterior a la Guerra del Marquesado de Villena, debe de reflejar muy bien el armamento existente unos años antes, especialmente por la sustitución que a lo largo del siglo XVI se hizo de los cañones de hierro por los de bronce, mucho más efectivos y seguros. Se trata de un armamento de mediano y pequeño calibre, donde los bolaños de piedra caliza encontrados en el castillo con unos diámetros de entre 30 a $20 \mathrm{~cm}$, lo que los situaría en un calibre medio-alto de bombarda, lo más probable es que sea munición de una trabuquera o un cuartago (Sousa, 1990), más propio del tiro curvo desde el interior de la fortaleza, que permite el disparo sin exponerse a los proyectiles del enemigo. De igual modo si se emplearon armas de fuego en el interior de las torres que flanquean la puerta, por el tamaño de la tronera y el escaso espacio interior, debieron ser armas del tipo falconete, cerbatana, ribaldoquín o cañón de mano.

En las excavaciones efectuadas en 1982, se recuperaron 42 bolaños de piedra y uno de hierro. De los de piedra, 13 tienen un 
diámetro de $29 \mathrm{~cm}, 7$ de $25 \mathrm{~cm}, 18$ de $18 \mathrm{~cm}$ y 4 de $16 \mathrm{~cm}$. El de hierro tiene $13 \mathrm{~cm}$. Los diámetros de los proyectiles de una bombarda estaban entre los 20 y $30 \mathrm{~cm}$ de diámetro, el pasavolante entre 14 y $20 \mathrm{~cm}$, el mortero entre 30 y $50 \mathrm{~cm}$, la trabuquera entre 20 y $30 \mathrm{~cm}$ y los cuartagos presentan una amplia variedad de calibres (Medina, 2004, p. 153).

En el Castillo de Almansa las obras de la reforma de don Juan Pacheco las podemos agrupar en dos tipos, las de carácter militar y las de función simbólica. Entre las primeras estaría la transformación de los accesos, dotando a los mismos de barbacanas defensivas, la transformación de las torres cuadradas en semirredondas mediante añadidos, la construcción de recintos inferiores con torres redondas y el emplazamiento de troneras de palo y orbe, mientras que entre las segundas estarían la edificación, por un maestro de obras prestigioso de la torre de homenaje, donde se aunasen todos los símbolos, conceptos y valores del nuevo señor y la heráldica por todo el edificio (Pretel, 1981; Simón, 2011, 2017 y 2019).

Sin embargo, no contamos por el momento con ningún inventario que nos indique cual fue el armamento de pólvora con el que pudo contar la fortaleza almanseña. El sitio de las tropas del capitán real Gaspar Fabra se limitó a cerrar las posibles salidas de los sitiados o la ayuda a los mismos desde el exterior y algún intento de butrón en el paño de muralla norte del edifico, que al parecer no tuvo éxito, ya que el cerco finalizó con la rendición de la fortaleza por su alcaide Gonzalo de Hellín, pese a haberse pertrechado de víveres y armas.

Quizás la excesiva verticalidad del castillo, agudizada por su emplazamiento hacía muy complicado el uso de la artillería, salvo el empleo de morteros o cortagos de tiro curvo, con una aparente escasa efectividad para rendir la plaza. El diámetro de las troneras nos indica que en caso de uso sería mediante bombardetas, cerbatanas y ribaldoquines (González, 2003, p. 93-96), armas de uso personal que podían ser orientadas en el sentido de la pendiente, muy acusadas hacia abajo, mientras que el uso de bombardas, independientemente del calibre parecía completamente desaconsejado. 
El sitio finalizó cuando la falta de ayuda exterior a los sitiados, el hambre y la peste acabaron con casi todos ellos, menos con el alcaide Gonzalo de Hellín, que rindió la fortaleza (Pereda, 1998, p. 93-96).

El conflicto se extendió a la mayoría de las poblaciones del marquesado, en especial en las que disponían de fortalezas, o bien donde los partidarios del marqués se habían refugiado o desde donde estos hostigaban a las fuerzas, generalmente los concejos, que se habían alzado contra su señor y manifestaron su apoyo a la causa real.

Se mencionan cercos en Jorquera, donde el recinto defensivo exterior, levantado en diferentes momentos tras la conquista cristiana, había sido reforzado en el acceso a la villa con una puerta defendida por dos torres, la de doña Blanca, una torre pentagonal con la proa hacia el exterior, edificada entre 1456 y 1458 por el marqués de Villena don Juan Pacheco, siendo maestro de obras Martín Sánchez de Bonifacio y su hijo, y la torre del Almez, de planta cuadrada, que en las fuentes aparece también con la denominación de «Daimez», donde se refugia el capitán realista Pedro Lisón en 1476, hasta su capitulación por orden de los reyes ante las fuerzas del marqués (Ortuño, 2005, p. 72). Como refuerzo de la defensa de ambas se excavó un foso en la roca, con un eje mayor de Norte a Sur de sección en ' $U$ ', en el apéndice de tierra que une de Este a Oeste el núcleo urbano con los caminos de acceso desde el exterior (Simón, 2011, p. 44-46). Un sistema similar de defensa se articuló en Alcalá del Júcar, donde se construyó un foso similar, se reforzó la muralla islámica con una torre circular y se construyó una torre de planta pentagonal con torrecillas en los ángulos posteriores.

Los refuerzos al complejo defensivo del castillo de Alarcón, con las torres exteriores del Campo, Alarconcillo, Cañavate y la torre de la Puerta del Bodegón, la torre del homenaje y las torres circulares del recinto defensivo hicieron imposible la toma por las tropas reales, pese al cerco establecido por Jorge Manrique y Pedro Ruiz de Alarcón como capitanes de las Hermandades de Toledo, y a Pedro Fajardo, Adelantado de Murcia (Ortuño, 2005, p. 47). 
Los cercos se extendieron al castillo de Iniesta, y al igual que en otros lugares se bloqueaban los accesos mediante cercas y abrojos con el fin de que tuvieran ayuda exterior, evitando salidas de los sitiados. El recinto defensivo de la fortaleza de Alcaraz se le dotó de cuatro bastiones, en cada una de sus esquinas, a modo de los que posteriormente conoceremos como revellín, para dificultar el bombardeo de las viejas torres cuadrangulares, por lo que presentan una cara exterior redondeada (SIMÓN, 2011, p. 229). El alzamiento de Alcaraz contra el marqués en 1475 supone el sitio de la fortaleza por don Pedro Manrique, sin llegar a aislarla completamente, por lo que pudo pedir refuerzos y recuperarla. Sin embargo, los acontecimientos se repitieron y esta vez la fortaleza alcaraceña fue ocupada y destruida (Torres, 1953), al igual que ocurrirá en Munera y Lezuza.

Si bien no tenemos datos de las fuerzas y métodos empleados, sí sabemos que en este teatro de operaciones don Pedro Manrique reúne un ejército formado entre otros por artillería, en concreto dos bombardas que provienen de Siles (Pretel, 1976, p. 17) y otras piezas menores, que serán utilizadas en el sitio del castillo de Riópar, causando daños en el acceso del castillo y en algunos paños de muralla próximos, lo suficientemente importantes como para ser una de las primeras tareas del nuevo alcaide manriqueño, ya que si no se reparaban la fortaleza estaba completamente expuesta. Los sitiados también contaban con armas de fuego, tal y como se recoge en el episodio del hijo del alcaide, el cual es capturado por los sitiadores y usado como parapeto conta los tiros de los sitiados (Pretel 1978, p. 150).

El equipamiento en estos momentos de fortalezas similares es muy parecido en todas ellas, de lo cual tenemos varios ejemplos. En el castillo de Pedraza de la Sierra ${ }^{8}$ se documentan 82 piezas, de las cuales tres son lombardas de gran calibre, además de tres cerbatanas, seis espindargas y cuatro espingardones como armas de

\footnotetext{
${ }^{8}$ El inventario se realiza en 1512 , con motivo del fallecimiento del condestable Bernardino de Velasco, por orden de la reina Juan I al alcaide Velasco de Temiño en la trasmisión de la fortaleza a Francisco Pérez de Barrandas (Franco y Soler, 1994 p. 308).
} 
calibre mediano y ligero, el resto no se llega a especificar, por lo que deben de ser armas del tipo ribaldoquín y culebrinas de mano. En la fortaleza de Torremormojón el inventario de 1506 señala ochenta y cuatro piezas de tiro de pólvora, un elevado número de piezas artilleras que lleva a Franco y Soler (1994, p. 325) a considerar a la fortaleza como un almacén o parque de artillería de campaña de la época.

Todo este complejo armamento requería de personal especializado, ya que el uso incorrecto de las piezas y la pólvora tenía unas graves consecuencias. Al final del siglo XV la organización de la artillería requería de personal con cometidos específicos, como los gastadores o sirvientes, dedicados a maniobras de fuerza, transporte y emplazamiento de los cañones; los ayudantes de artillero, con posibilidades de ascenso a tiradores o artilleros ordinarios, y en un nivel superior los cañoneros o lombarderos, con posibilidades de ascender a gentiles-hombres, los cuales comenzaron a ser reconocidos como ingenieros, los cuales, aparte de sus conocimientos genuinamente artilleros, debían entender sobre cuestiones técnicas, como fundición de cañones, medición de distancias, o trazado de baterías y trincheras (Mora, 2004, p. 387).

En algún caso conocemos el número y el sueldo de estos especialistas. Así de la Guerra del Marquesado disponemos de la relación de gastos que el conde Cocentaina pretende que le sean abonados por los Reyes Católicos por lo sitios de Sax y Chinchilla. En Sax el conde dispone de 8 espingarderos y un número no especificado de lombarderos, los cuales estuvieron 94 en el caso de los primeros y 111 días los segundos, es decir, estuvieron presentes desde los preparativos, el 16 de marzo, hasta la rendición de la fortaleza el 4 de julio de 1476. Llama la atención de la individualización de un «vizcaíno», precisamente el que consiguió abrir la brecha en la muralla con el uso de pólvora, por lo que debía ser o un experto en artillería o el encargado de fabricar la pólvora ${ }^{9}$. Los «fusteros» debían

\footnotetext{
${ }^{9}$ Las principales ferrerías del momento estaban en la zona catalana y vasca, donde la fabricación de piezas de hierro tenía una larga tradición desde la Antigüedad.
} 
ser personal de apoyo de la artillería, ya que serían los encargados de las cureñas y manteletes de protección, además de fabricar otras defensas para los caballeros y peones (Sáez, 1982, p. 589). Del conjunto total de tropas que el conde desplazó hasta la fortaleza de Sax, solo un $10 \%$ estaban relacionados con las armas de fuego, lo cual muestra su escasez y alto coste en esos momentos.

Además de ello aportó pólvora, salitre, azufre y carbón para efectuar una cantidad no especificada de pólvora, las citadas lombardas, clavos, madera y piedras para las cureñas y bolaños, escaleras, coces y tacos para el servicio de otras armas de fuego, tanto de su montaje como de su uso.

En el caso del sitio de Chinchilla, las fuerzas del conde relacionadas con las armas de fuego son nuevamente los 8 espingarderos y el número no especificado de lombarderos, que han sido trasladados desde Sax a Chinchilla, empezando el cerco el 14 de julio. Acompañan a estas fuerzas los carpinteros de apoyo y se aporta un material consistente en pólvora y salitre, carros para mover las piezas, un trabuco y peratacos (Sáez, 1982, p. 590).

Como se puede apreciar se trataba de un número reducido dentro del contingente de fuerzas del conde para sitiar la fortaleza, sin embargo, la artillería y las armas de fuego individuales están ya consolidadas en los conflictos bélicos del siglo XV, especialmente en los sitios de plazas fuertes, siendo los responsables, en este caso, de la rendición de Sax, frente a la guerra de escaramuzas ${ }^{10}$ tan común en otros escenarios, como el entorno de Garcimuñóz y Alarcón, donde se produce el episodio de la muerte de Jorge Manrique. Es un personal adscrito a la casa señorial, de alto prestigio que en ocasiones llegarán a ser hombres de confianza y que dirigen a un equipo de artilleros muy especializado (Castro de y Mateo, 2018, p. 106-107).

\footnotetext{
${ }^{10}$ La táctica del "torna fuga" fue muy empleada por la caballería ligera islámica en la península ibérica, a diferencia de otros escenarios europeos donde la caballería pesada era lo habitual. Esta táctica pasó al bando cristiano y se mantuvo hasta la organización y tácticas de los ejércitos de la Edad Moderna.
} 


\section{CONCLUSIONES}

El mortero y la bombarda de hierro, junto con los bolaños de piedra y algunos de los proyectiles de hierro esféricos hallados en la excavación del Castillo de Chinchilla, son una muestra de la materialidad de un acontecimiento histórico de singular relevancia, no solo para el actual territorio albaceteño, sino para el ámbito nacional y la prueba de un proceso tecnológico que empezó a cambiar la sociedad y la geografía europea. La Guerra del Marquesado (1475-1480) fue el preludio a la Guerra de Granada (1482-1492) (Fig. 6) y ambas del despegue definitivo de las características y circunstancias de los nuevos conflictos de la Edad Moderna.

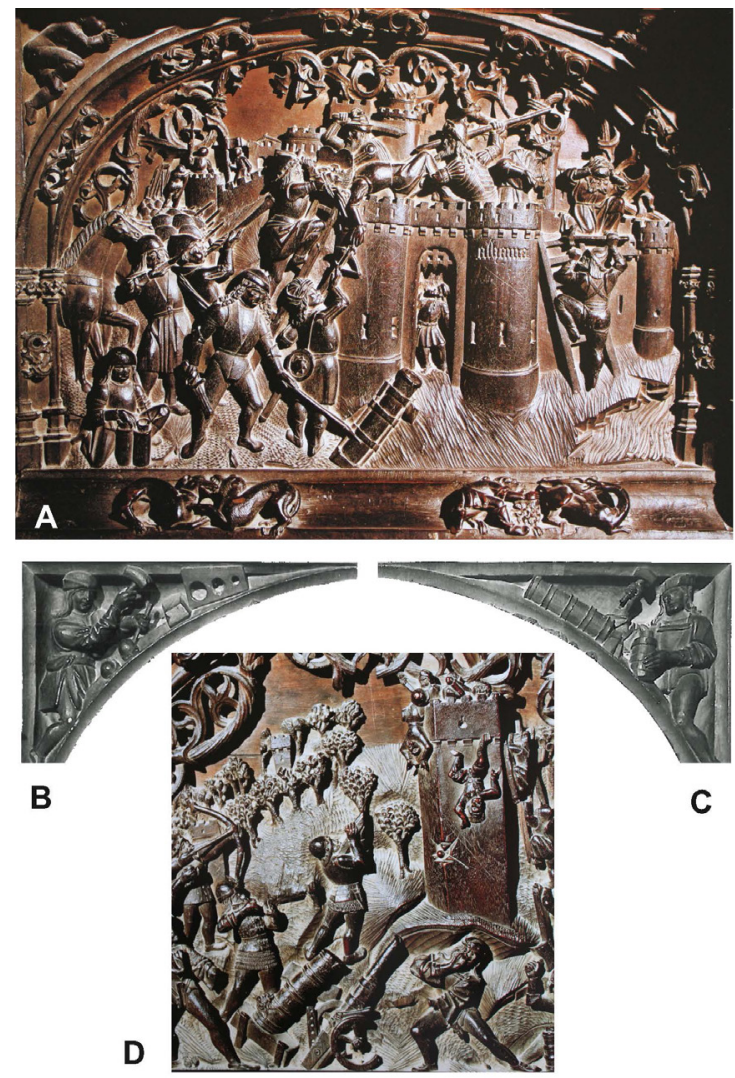

Fig. 6.- Detalles de la sillería del coro bajo de la Catedral de Toledo. A. Tablero 1: Asalto y conquista de Alhama (1482). B. Enjuta con cantero labrando un bolaño, C, Enjuta con un artillero cargando la recamara de una lombarda. D. Tablero 26, sitio de una plaza por la artillería. (Valdés, 2004). 
Su generalización era un proceso creciente desde la aparición de las armas de fuego a principios del siglo XIV, y su rápido desarrollo supuso la modificación de las técnicas de sitio y la adaptación de las fortalezas para resistir en un primer momento el envite de este tipo de armas y pasar posteriormente a la ofensiva a partir de las primeras décadas del siglo XVI.

En las piezas artilleras de Chinchilla se aprecian las toscas técnicas de fabricación y los límites de los conocimientos de sus creadores, los cuales las fabricaban a partir de láminas de hierro en caliente, resolviendo los problemas de resistencia y carga con unos métodos que pronto se verían superados por la fundición en hierro y sobre todo bronce, donde la avancarga y la mejora en el alma de las piezas supuso una mayor carencia de tiro, una mayor fiabilidad y sobre todo una mayor precisión en el disparo, aumentado la efectividad y con ellas su eficacia, por lo que no es de extrañar que a partir de ese momento la inversión económica que suponía su materialización tuviera unos altos rendimientos en el campo de batalla.

Su creciente importancia queda patente en los escasos inventarios que nos han llegado de las fortalezas del marquesado de Villena, donde se indican de forma individualizada las piezas de fuego de uso individual o las piezas y tipos de las artilleras, indicando su estado de operatividad, los elementos necesarios para su funcionamiento, como cureñas y mechas, junto con las materias primas para realizar la pólvora. Los altos costes de funcionamiento son demandados por la nobleza, en este caso el III conde de Cocentaina, en favor de la causa realista, especificando, para justificar la cantidad solicitada, el manifiesto de los efectivos humanos con armamento de fuego y piezas artilleras aportadas, junto con todo lo necesario para su empleo, especialmente la pólvora, dado su alto coste de elaboración por artesanos especializados.

Los efectos de la artillería en los sitios a las fortalezas del marquesado fueron muy diferentes. En el caso de Sax se consigue, tras abrir una brecha en la muralla exterior, la capitulación del alcaide, el cual no esperaba ayuda exterior alguna por parte de las fuer- 
zas del marqués. En Jumilla el simple cerco y sitio lleva al alcaide a cambiar de bando. En Almansa la fortaleza se rinde tras un contundente sitio y la propagación de la enfermedad entre sus moradores. En Villena, la fortaleza capitula ante la perspectiva similares a las de otras fortalezas del marquesado. En el resto de las fortalezas se dan escaramuzas, sitios breves o intercambios de proyectiles de todo tipo sin mayores consecuencias.

El caso más significativo es el de la fortaleza de Chinchilla, donde los sitiadores no consiguen rendir la fortaleza, pero evitan que no se preste ayuda desde la principal plaza de este sector del marquesado a las otras, lo que provoca el desmoronamiento progresivo a la causa del marqués. En este caso el intercambio artillero debió de ser muy violento, hasta el punto de que se causaron daños muy graves en el caserío de la población, en especial en el entorno de los lugares donde se emplazó la artillería de sitio, con especial incidencia en el entorno de la Iglesia del Salvador (San Julián).

Las consecuencias políticas, sociales y económicas en Chinchilla y en el resto del marquesado han sido ampliamente analizadas por autores como Pretel (2002) y Ortuño (2005) por lo que no es necesario volver sobre ellas. En el caso que nos ocupa, en la fortaleza chinchillana debieron de quedar las piezas más antiguas, de menor potencia o inservibles, como son la bombarda trabuquera o mortero y los restos de la caña de la bombarda, que por la deformación de su junta con la recamara pudo haber quedado inservible, quedando olvidadas hasta el punto de ser sepultadas por los movimientos de tierra y las reformas acometidas en el castillo para adecuarlo a las nuevas necesidades militares. El resto de las piezas artilleras, las más operativas, debieron de ser desplazadas a lugares con mayor control del marqués, el cual para intentar recobrar la confianza y el aprecio de los monarcas participó y aportó hombres y artillería a la Guerra de Granada y posteriormente a los ejércitos del emperador Carlos V, sin que ello tuviera efectos para su causa hasta su muerte (Fig. 7). 

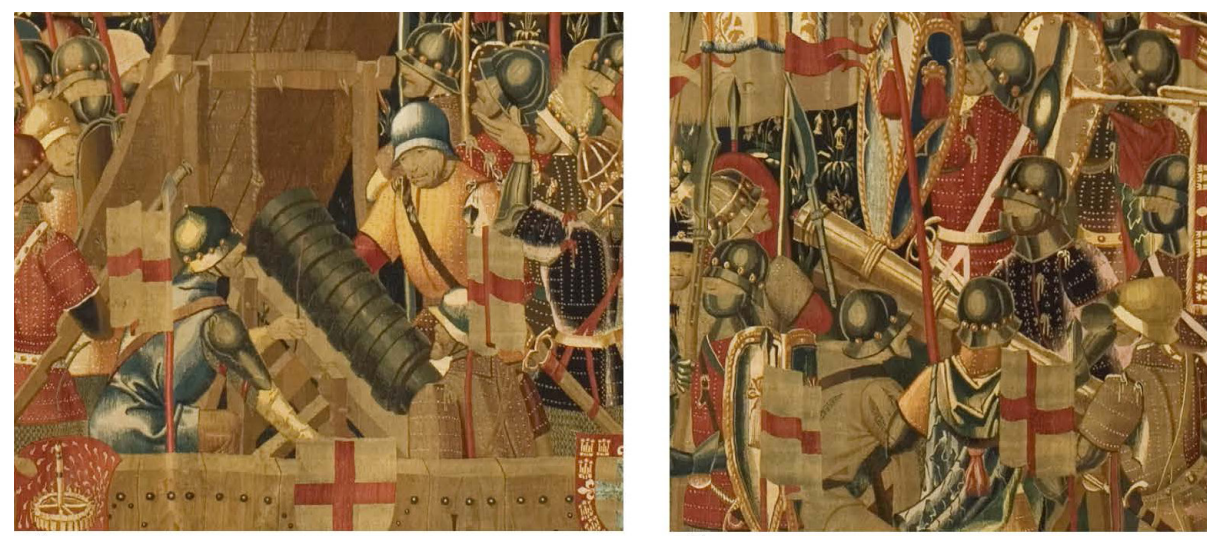

A
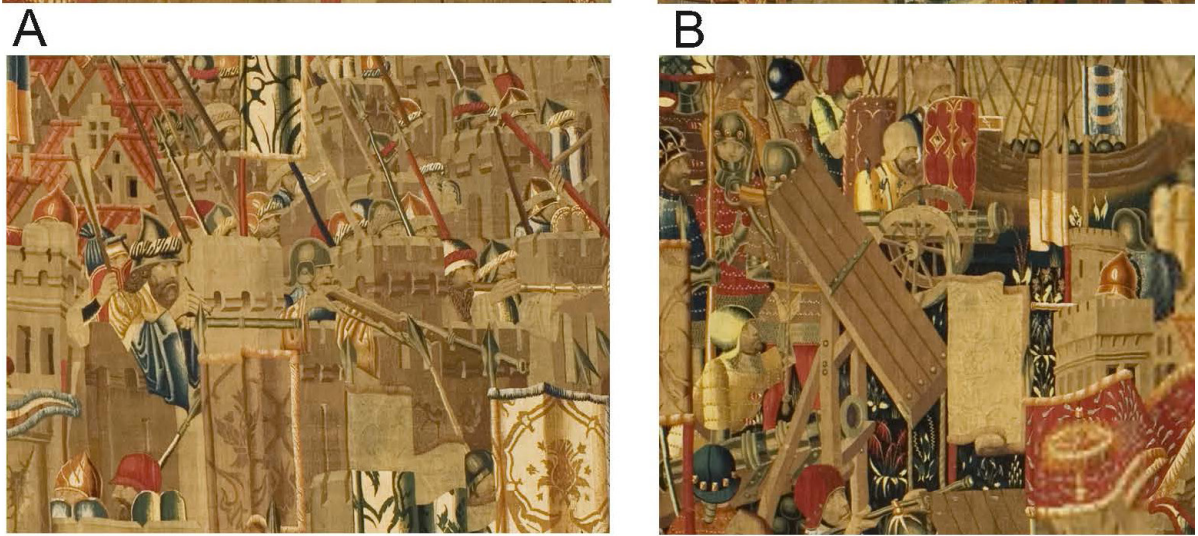

C

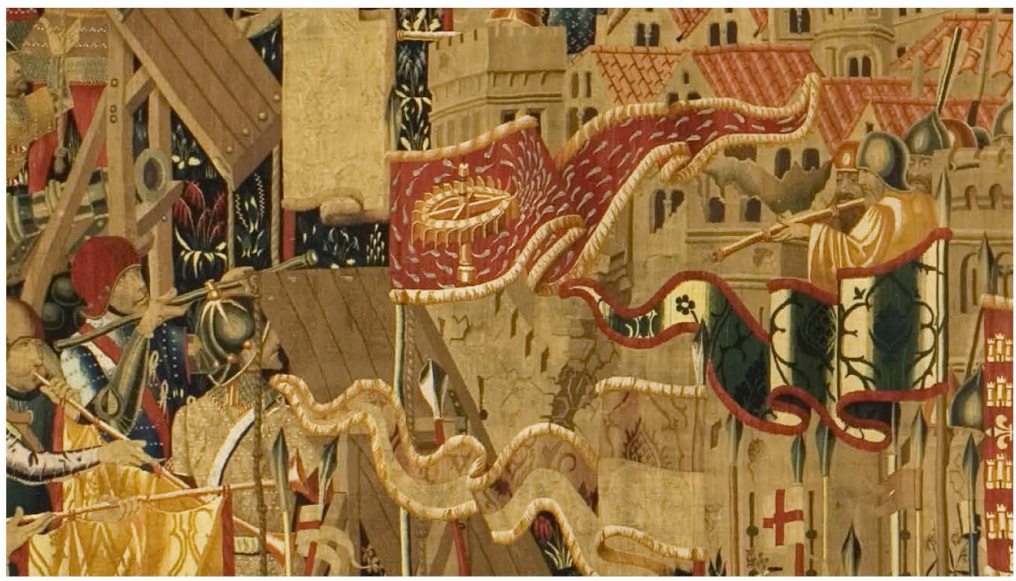

\section{E}

Fig. 7.- Colegiata de Pastrana. Tapiz del Sitio de Arzila (20-24 de agosto de 1471) por Alfonso V de Portugal. Detalle del uso de lombardas de hierro y bronce, por parte de los sitiadores, y ribadoquines, falconetes y cerbatanas, por parte de los sitiados. 


\section{REFERENCIAS BIBLIOGRÁFICAS}

ARÁNTEGUI y SANZ, J. (1887). Apuntes históricos sobre la artillería española en los siglos XIV y XV. Establecimiento Tipográfico de Fortanet.

ARNEDO LÁZARO, J.V. (2013). ¡QUE VIENEN LOS FRANCESES! - El sitio de Castillo de Villena en su «200 aniversario» y operaciones paralelas 1813-2013. Fundación Municipal José María Soler.

CASTILLO CÁCERES. F. (2004). Guerra, ejército y sociedad en el reinado de Isabel la Católica. En Valdés, A. (Coord). Artillería y Fortificaciones en la Corona de Castilla durante el Reinado de Isabel la Católica 1474-1504, (pp. 23-59).

CASTRO FERNÁNDEZ, de J. J. (2004). Los ingenieros reales de los Reyes Católicos. Su nuevo sistema de fortificación. En Valdés, A. (Coord), Artillería y Fortificaciones en la Corona de Castilla durante el Reinado de Isabel la Católica 1474-1504. (pp. 321383).

CASTRO FERNÁNDEZ, de, J. J. y CUADRADO, Á. (2004). «Los artilleros de los Reyes Católicos», Cobos, F. (Coord). La artillería de los Reyes Católicos. Junta de Castilla y León: (pp. 62-89 y 138-147).

CASTRO FERNÁNDEZ, de, J. J. Y MATEO DE CASTRO, J. (2016): “Ingenieros y artilleros en la Guerra de las Comunidades de Castilla”. Eds. Enrique Martínez, Jesús. Cantera y Magdalens. De Pazzis, La organización de los Ejércitos, Volumen I. Madrid, Cátedra Extraordinaria Complutense de Historia Militar: 538-593.

CASTRO FERNÁNDEZ, de, J. J. Y MATEO DE CASTRO, J. (2018): “La artillería en el reino de Castilla y León durante el siglo XV". Gladius XXXVIII, 99-124.

COBOS GUERRA F. (2002). Artillería y fortificación ibérica de transición en torno a 1500, En Mil Anos de Fortificaçoes na península Ibérica e no Magreb (500-1500). Simpósio Internacional sobre Castelos, 2000. (pp. 677-696). 
COBOS GUERRA, F. (coord.) (2004). La artillería de los Reyes Católicos. Junta de Castilla y León.

COBOS GUERRA, F. y DE CASTRO FERNÁNDEZ, J.J. (2000). Artillería y Poliorcética en las Estrategias de Fernando el Católico contra Francia (Documentos para su Estudio). Gladius (XX), 251-268.

COOPER, E. (1991). Castillos Señoriales en la Corona de Castilla. Junta de Castilla y León.

COOPER, E. (2002). Desarrollo de la fortificación tardomedieval española. En Mil Anos de Fortificaçoes na península Ibérica e no Magreb (500-1500). Simpósio Internacional sobre Castelos, 2000. (pp. 667-676).

COOPER, E. (2012). El dominio de la pólvora en la arquitectura militar a finales de la Edad Media. En IV Congreso de Castellología. (pp. 97-110).

COOPER, E. (2014). La fortificación de España en los siglos XIII y XIV. Ministerio de Defensa y Marcial Pons Historia.

FRANCO SILVA, A. (2005). Entre la Derrota y la Esperanza. Don Diego López Pacheco, Marqués de Villena. Universidad de Cádiz.

FRANCO SILVA, A. (2012). Juan Pacheco, privado de Enrique IV de Castilla. La pasión por la riqueza y el poder. Servicio de Publicaciones de la Universidad de Cádiz, Granada y Sevilla.

FRANCO SILVA, A. Y SOLER DEL CAMPO, A. (1994). Los arsenales de dos fortalezas castellanas: Inventarios de Torremormojón (1506) y Pedraza de la Sierra (1512). Historia, Instituciones y Documentos, (21), 309-344.

GIL SANJUÁN, J. y TOLEDO NAVARRO, J.J. (2008). Importancia de la artillería en la conquista de las poblaciones malagueñas (1485-1487). Baetica (30), 311-331.

GONZÁLEZ ALCALDE, J. (1997). La media culebrina del Marqués de los Vélez. La transición de la artillería de hierro a la de bronce. Militaria (10), 365-376.

GONZÁLEZ ALCALDE, J. (2000). Las dos bombardas de la Condesa de Montijo. Inicios y desarrollo de la Artillería de hierro forjado en la Baja Edad Media. Militaria (14), 147-155. 
GONZÁLEZ ALCALDE, J. (2003). Bombardeta, cerbatana, ribadoquín, falconete y cañón de mano. Cinco piezas multifuncionales de la artillería. Militaria (17), 97-110.

HERNÁNDEZ CARRIÓN, E. y SIMÓN GARCÍA, J.L. (2015). El Castillo de Jumilla: Historia de un centinela. Ayuntamiento de Jumilla. HERRERO FERNÁNDEZ-QUESADA, M.D. (2004). La artillería de los Reyes Católicos. Procedencia y semblanza. En Valdés, A. (Coord). Artillería y Fortificaciones en la Corona de Castilla durante el Reinado de Isabel la Católica 1474-1504, (pp. 268319).

IZQUIERDO MENCÍA, D. (2011). Castillo de Chinchilla de Montearagón: una visión arqueológica. Al-Basit (56), 169-203.

LÓPEZ MARTÍN, F.J. (2005). La evolución de la artillería en la segunda mitad del siglo XV. El reinado de los Reyes Católicos y el contexto europeo. En Valdés, A. (Coord). Artillería y Fortificaciones en la Corona de Castilla durante el Reinado de Isabel la Católica 1474-1504. (pp. 181-223.)

LÓPEZ MARTÍN, F.J. (2008). Artillería y fortificación en el contexto norteafricano. Aldaba (34), 13-43.

LÓPEZ MARTÍN, F.J. (2011). Escultura para la Guerra. La creación y evolución de la artillería hasta el siglo XVII. Consejo Superior de Investigaciones Científicas,

LORRIO ALVARADO, A.; SIMÓN GARCÍA, J.L. Y SÁNCHEZ DE PRADO, M.D. (2014). La Peña del Castillo (Peñas de San Pedro, Albacete): de oppidum ibérico a fortaleza cristiana. Lucentum (XXXIII), 73-112.

MEDINA ÁVILA, C.J. (2004). La artillería española en el reinado de los Reyes Católicos, La época de los artilleros empíricos y el despertar de un arma. En Valdés, A. (Coord). Artillería y Fortificaciones en la Corona de Castilla durante el Reinado de Isabel la Católica 1474-1504. (pp. 112-155).

MORA FIGUEROA, l. (2002). Transformaciones artilleras en Ia fortificación tardomedieval española. En Mil Anos de Fortificaçoes na Península Ibérica e no Magreb (500-1500), (pp. 651-658). 
MORA PIRIS, P. (2004). La artillería: aproximación y materiales. En Silva Suárez, M. (Coord). Técnica e ingeniería en España. (Vol. I). (pp. 381-400).

MUÑOZ JIMÉNEZ, J.M. (2005). El arquitecto Juan Guas (a. 14531496). La primera fortificación española de transición y los modelos italianos. En Ruibal, A. (Coord). Actas del III Congreso de Castelloogía Ibérica. (pp. 609-632.)

OCHOA GARCÍA, A. (2017). Inventario de los bienes del castillo de Sax en el año 1492 (Día Internacional de los Archivos). Blog Museo Virtual de la Villa de Sax. https://museodelavilladesax. wordpress.com/2017/06/08/inventario-de-los-bienes-delcastillo-de-sax-en-el-ano-1492-dia-internacional-de-los-archivos/

OCHOA GARCÍA, A. (2018). La bombarda «la Duquesa» en el castillo de Sax. Blog Museo Virtual de la Villa de Sax. https://museodelavilladesax.wordpress.com/2018/11/15/ la-bombarda-la-duquesa-en-el-castillo-de-sax/

ORTUÑO MOLINA, J. (2002). La vinculación de la fortaleza de Almansa a la familia Fabra. En II Congreso de Historia de Albacete. (Vol. 2), (pp. 181-192).

ORTUÑO MOLINA, J. (2005). La fortaleza de Chinchilla durante la Guerra del marquesado de Villena (1476-1480). Instituto de Estudios Albacetenses «Don Juan Manuel».

PAZ, J. (1914). Castillos y fortalezas del reino. Noticia de su estado y de sus Alcaides durante los siglos XV y XVI. Imp. Archivos, Bibliotecas y Museos.

PEREDA HERNÁNDEZ, M.J. (1998). Moros, mudéjares, moriscos y cristianos en Almansa. En Jornadas de Estudios Locales, (2) (pp. 43-98).

PRETEL MARÍN, A. (1976). Noticias sobre el castillo de Riópar en la Edad Media. Al-Basit (2), 7-24.

PRETEL MARÍN, A. (1978). Una ciudad castellana en los siglos XIV y XV. (Alcaraz 1300-1475). Instituto de Estudios Albacetenses «Don Juan Manuel». 
PRETEL MARÍN, A. (1981). Almansa medieval. Una villa del señorío de Villena en los siglos XIII, XIV y XV. Ayuntamiento de Almansa.

PRETEL MARÍN, A. (1986-1987). Los gastos militares de Chinchilla en el cerco de 1476. Anales del Centro Asociado de Albacete, (8), 165-188.

PRETEL MARÍN, A. (1987). En torno a la sublevación de Chinchilla y el cerco de su castillo en 1476. En Homenaje al Profesor Juan Torres Fontes, (Vol. 2). (pp. 1340-1358). Universidad de Murcia y Academia Alfonso X.

PRETEL MARÍN, A. (1992). Chinchilla medieval. Instituto de Estudios Albacetenses «Don Juan Manuel».

PRETEL MARÍN, A. (2002). La guerra sucesoria de los Reyes Católicos (1475-1480) y sus repercusiones dentro del marquesado de Villena. En II Congreso de Historia de Albacete, 2000, (Vol 2) Edad Media, (pp. 115-150).

PRETEL MARÍN, A. (2011): El señorío de Villena en el siglo XV. Instituto de Estudios Albacetenses «Don Juan Manuel».

SÁEZ SÁNCHEZ, C. (1982). Los sitios de Sax y Chinchilla en la conquista del Marquesado de Villena. Anuarios de Estudios Medievales (12), 585-596.

SIMÓN GARCÍA, J.L. (2011). Castillos y Torres de Albacete. Instituto de Estudios Albacetenses «Don Juan Manuel».

SIMÓN GARCÍA, J.L. (2017). El castillo de Almansa en el Marquesado de Villena. En Jornadas de Estudios Locales (11), (pp. 23-51).

SIMON GARCÍA J.L. (2019). Poliorcética artillera en los castillos del Marquesado de Villena. El castillo de Jumilla. En Hernández Carrión, E; José Miguel García Cano, Juan Gallardo Carrillo, Francisco Ramos Martínez (Eds.). Estudios de arqueología en homenaje a Francisco Gil González. (pp. 37-48).

SIMON GARCÍA, J.L. y SEGURA HERRERO, G. (2002): La torre del homenaje del Castillo de Sax: análisis, propuestas y preguntas. El Castillo de Sax (13), 26-31. 
SIMÓN GARCÍA, J.L., LORRIO ALVARADO, A.J., SÁNCHEZ DE PRADO, M.D. Y MONEO RODRÍGUEZ, T. (2017). Armamento de sitio en el castillo de Chinchilla (Albacete) durante la Guerra de la Independencia: artillería y granadas de mano. Gladius (XXXVII). 171-206.

SOLER DEL CAMPO, A. Y FRANCO SILVA, A. (1994). Los arsenales de dos fortalezas castellanas: inventarios de Torremormojón (1506) y Pedraza de la Sierra (1512). Historia. Instituciones. Documentos, 309-344.

SOLER GARCÍA, J.M. (1969). La relación de Villena de 1575. Instituto de Estudios Alicantinos.

SOUSA Y FRANCISCO, A. (1990). 600 años de artillería. Evolución de los materiales de artillería y sus municiones. En Folletos sobre la historia de la artillería en el antiguo Museo del Ejército de Madrid.

TORRES FONTES, J. (1953). La conquista del Marquesado de Villena en el reinado de los Reyes Católicos. Hispania (50), 37-151.

VALDÉS, A. (coord.) (2004). Artillería y Fortificaciones en la Corona de Castilla durante el reinado de Isabel la Católica (14741504). Ministerio de Defensa.

VIGÓN, J. (1947). Historia de la Artillería Española, (vol. I), CSIC. 